\title{
Synthesis Methods for Nanoparticle Morphology Control in Energy Applications
}

\section{February 2022}

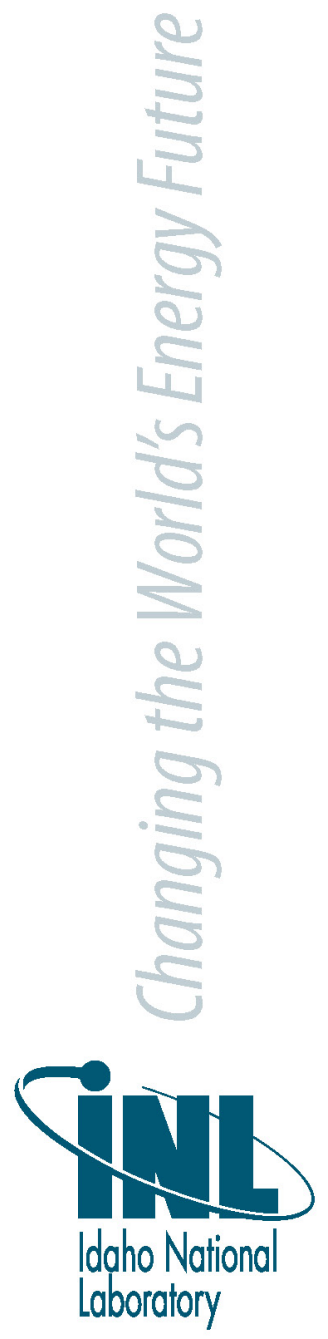

Joy Margaret Morin, Kiyo T Fujimoto, Arin Seth Preston, Donna Post Guillen 


\section{DISCLAIMER}

This information was prepared as an account of work sponsored by an agency of the U.S. Government. Neither the U.S. Government nor any agency thereof, nor any of their employees, makes any warranty, expressed or implied, or assumes any legal liability or responsibility for the accuracy, completeness, or usefulness, of any information, apparatus, product, or process disclosed, or represents that its use would not infringe privately owned rights. References herein to any specific commercial product, process, or service by trade name, trade mark, manufacturer, or otherwise, does not necessarily constitute or imply its endorsement, recommendation, or favoring by the U.S. Government or any agency thereof. The views and opinions of authors expressed herein do not necessarily state or reflect those of the U.S. Government or any agency thereof. 


\section{Synthesis Methods for Nanoparticle Morphology Control in Energy Applications}

Joy Margaret Morin, Kiyo T Fujimoto, Arin Seth Preston, Donna Post Guillen

February 2022

Idaho National Laboratory

Idaho Falls, Idaho 83415

http://www.inl.gov

Prepared for the

U.S. Department of Energy

Under DOE Idaho Operations Office

Contract DE-AC07-05ID14517 


\title{
Synthesis Methods for Nanoparticle Morphology Control in Energy Applications
}

\author{
Joy Morin, Kiyo Fujimoto, Arin Preston and Donna Post Guillen \\ Idaho National Laboratory, Idaho Falls, Idaho 83415
}

\begin{abstract}
Lightweight nano-composite materials, nano-coatings, nanocatalysts, and nano-structured materials have demonstrated an ability to reduce emissions and maximize clean energy production. Nanoparticles play an important role in engineering and decarbonization for energy applications, and a wide range of nanoparticle synthesis methods have been developed to include those that enable control over particle morphology. The ability to control nanoparticle morphology allows the tailoring and improvement of material properties that will accelerate efforts towards lowering carbon emissions by developing advanced catalysts for carbon sequestration and will enhance energy efficient processes and technologies. Synthesis methods aimed towards shape control of nanoparticles have demonstrated an ability to form spheres, rods, flower-like shapes, cubes, plates, shells, and chiral geometries. Processing methods used to form these morphologies include microwave assisted synthesis, solvothermal, hydrothermal, and a wide range of capping agents. A discussion of a few of these methods is given along with results and applications.
\end{abstract}

Keywords: Nanoparticles; Morphology control; Synthesis; Decarbonization; Clean energy

\section{Introduction}

Nanoparticles are classified as "a particle that ranges from 1-100 nanometers in size [1]." Specific mechanical properties of a material, like stiffness, tensile strength, and hardness [2], vary and are determined by the size and shape of the nanoparticles [3]. Some common shapes that a nanoparticle can form are spheres (Figure 1), rods (Figure 1), flower-like shapes (Figure 2), cubes (Figure 3), plates (Figure 4), shells (Figure 5), and chiral geometries (Figure 6). Although these shapes can naturally form, there are ways to control which shapes particles form. To intentionally achieve and control these shapes, shape control processes must be used. Many shape control methods use a "bottom-up" approach, where the formation begins with atomic agglomeration, or by modification of simple "seed" particles, and builds up into a shaped particle. Such bottom-up methods proceed by atomic deposition in chemical, microwave, or thermal environments using supplied capping agents and precursors. When using a topdown approach, the shape is harder to control during synthesis [4]. In the top-down approach, material is taken away to form a product which is more difficult to precisely control than synthesizing and building up material chemically. The top-down approach is also typically more expensive [5]. Both thermodynamics and kinetics play are driving forces in nanoparticle synthesis. Kinetics refers to a stabilized facet leading to the "most favorable pathway towards 
the final product," while thermodynamics refers to said stabilized facets as leading "to the most stable final product [6].". During a thermodynamic process, the surface free energy of the particles decreases and forces the particle into a certain shape. Shape control processes can use either thermodynamics, kinetics, or a combination of the two during synthesis [7]. The ability to control the shape of a particle provides numerous advantages such as self-assembly [8, 9], increased plasmonic absorbance [10], and improved catalytic activity [5, 11]. Multiple materials can be formed using shape synthesis. Metals and ceramics are synthesized for electronic improvements [12], clean energy applications [13,9], and decarbonization efforts among other applications [14].

\section{Motivation}

The ability to control nanoparticle shape during synthesis has several benefits. Things like carbon emissions [13], catalysts [5, 11], self-assembly [9], battery efficiency [12], and more can be improved. Although clean energy has made advances in the past, specific nanoparticle geometry can provide more benefits than before. "Shape... plays a major role in how particles are transported through a fluid, especially within narrow tubes [15]" which is the environment of nanofluids used for heating and cooling systems. An example of how shape is important in decarbonization specifically can be seen in solar collection that takes advantage of nanoparticles [14]. Shapes with more sharp corners and edges can support larger plasmonic electric field enhancements than shapes without [10]. In another study by Zhu, W., et al., it was found that Pd nanoparticles with an octahedral shape showed higher CO selectivity (up to 95\%) and better activity than Pd nanoparticles that were synthesized as cubes [16]. These Pd particles are used to reduce $\mathrm{CO}_{2}$ into a synthesis gas. With higher $\mathrm{CO}$ selectivity, this process can be done more efficiently.

Catalysts are also a large part of the motivation for shape control. Different shapes of particles will have different surface facets. These surface facets will respond differently with other molecules and can lead to a more efficient interaction with said molecule [5]. This will cause an increase in catalytic activity which can save time and energy by having a faster reaction that may not require something like heat to act as a catalyst. Catalysts play a major role in reducing carbon emissions. They can be used to convert carbon into other useful materials like alcohol, so the better the catalyst, the more carbon that can be converted. Catalysts can also be used in the production of hydrogen. With improved catalysts, water can be split in a renewable way to create hydrogen and can replace more pollutant methods [11].

Another important factor of shape control is the promotion of self-assembly among the nanoparticles. When particles are a certain shape like cubes, there is more self-assembly than other shapes like a sphere. This increased self-assembly can be used to create networks of nanoparticles that can help fabricate functional devices like catalysts and targeting [3]. Applications of these self-assembled networks include oil spill clean-up, toxic metal removal, and removal of dyes in water [9]. Because of the bottom-up formation of these nanonetworks, the pathways can be potentially controlled by programming molecular-scale information by simple organic synthesis [9]. Some of these self-assembled networks allow solid-like phases to interact with liquids, leading to the removal of pollutants in water mentioned earlier.

Improving battery efficiency is another area benefitted by shape control synthesis. A study by Seher, J., et $a l$. showed that when $\mathrm{LiFePO}_{4}$ nanoparticles had a plate-like shape, they showed an increase in electrochemical performance and fast-charging capability compared to nanoparticles with a rodlike shape [12]. This means batteries using plate-like particles would have a faster charging time and improved reliability, leading to less wasted energy and less contribution to pollution.

Other energy efficiency improvements like in electricity play a role in reducing carbon emissions while being affected by nanoparticle shape control. Thermoelectric power generation is a process that takes waste heat and converts it to usable electric power [13]. The conversion efficiency in this process can be improved based on the shape of nanoparticle used. In a study by Han, L., et al., Al-doped $\mathrm{ZnO}$ particles were synthesized into rods and platelets [13]. Platelets that had aligned laminar grains had a better conversion efficiency than the rods and other platelets synthesized, which would benefit the prevention of carbon emissions. 


\section{Methods and Outcomes}

There are numerous ways to control the particle shape during nanoparticle synthesis. Four main types of synthesis exist under the umbrella of thermodynamics and kinetics including using different capping agents, microwave heat treatment, autoclave heat and pressure treatment, and using different solvents and precursors at different concentrations.

Capping agents not only provide stability to nanoparticles by preventing agglomeration of colloidal particles, but also restrict their growth. Capping agents have a hydrophobic tail and a hydrophilic head that bond to the nanoparticles. Some capping agents that are used in nanoparticle synthesis include small ligands, surfactants, polysaccharides, cyclodextrins, polymers, and dendrimers [17]. One way that capping agents are used is in creating electrocatalysts to increase the efficiency of polymer electrolyte fuel cells (PEFCs) [18]. A study by Safo, I. A., et $a l$. attempts to accelerate the oxygen reduction reaction (ORR) by creating shape-controlled nanoparticles to "modify the adsorption of reactants to the surface [18]." PVP (polyvinylpyrrolidone) and OAm (oleylamine) were the two capping agents that were used and compared for the Pt nanocubes that were synthesized. The PVP capping agents created smaller particles than the OAm capping agents, and the OAm particles synthesized as spheres that "showed significantly higher electrochemically active surface area and ORR activity than the PVP" particles [18]. This spherical shape created a better catalyst for the ORR. This is because the surfaces of cubes are comprised of (100) facets, which are very low-index, low surface energy. The surface of a sphere will have numerous facets types, and many of those will have high surface energy. Another example of capping agents being used to synthesize nanoparticles while controlling shape is called solution-phase synthesis. A study by Sun, Y., et al. uses metal nanoparticles to synthesize hollow interior nanostructures [19]. A shape that has a hollow interior will have higher surface areas compared to an equivalent solid structure, which often leads to greater reactivity [5]. An oxidationreduction (redox) process called the galvanic replacement reaction was used to control the "molar ratio between Ag and AuCl4-(aq) precursor added into the reaction mixture [20]." This allowed for control of the structure of the final material.

Microwave synthesis is a method that provides a temperature change when forming the nanoparticles. The reduction rate of the precursor monomer rapidly increases in the solution, and this affects the particle formation shape. This process is used over other heating methods like heating in a water or oil bath because of the decrease in processing time [21]. A study conducted by Wang, W., et al. on zinc oxide particle synthesis showed that different microwave temperatures produced different particle shapes when using an ionic liquid [BMIM] $\mathrm{BF}_{4}[22]$. When the microwave was set to $50{ }^{\circ} \mathrm{C}$, flower-like particles of $\mathrm{ZnO}$ were synthesized. While under the same conditions but changing the temperature to $125^{\circ} \mathrm{C}$, needle-like shapes were synthesized. In between those temperatures at $90{ }^{\circ} \mathrm{C}$, both flower-like and needle-like particles of $\mathrm{ZnO}$ were synthesized, showing that changing the temperature during microwave synthesis can affect the shape of particle being synthesized. While the advantages of the flower-like shape compared to the needle-shape particles were not studied in this experiment, it proves that microwave synthesis is a form of shape control synthesis.

An autoclave is another tool used for shape control during nanoparticle synthesis. Autoclaves can reach temperatures and pressures that other methods can't. Shape synthesis using an autoclave is beneficial due to fact that "the controlled environment provided by the autoclave ensures that the best possible physical properties are reputably attainable and repeatable [23]." A study by Mi, Y., et al. used the hydrothermal method in an autoclave to produce carbon micro-spheres [24]. By using a combination of a water and glucose precursor $(50 \mathrm{ml}$ and $4.0 \mathrm{~g}$ respectively) with a $500{ }^{\circ} \mathrm{C}$ furnace, carbon micro-spheres were obtained after 12 hours in the oven. When the experiment was repeated at lower temperatures of 300 and $400{ }^{\circ} \mathrm{C}$, no carbon micro-spheres were obtained. These spheres are beneficial in the production of lithium-ion secondary batteries, and "high-density and high-strength carbon artifacts [24]." Cha, H. G., et al. shows how pressure can affect nanoparticle shape in a study where "different shaped metal nanocrystals were prepared by annealing time and vacuum pressure and each have a highly crystalline structure [25]." When under a vacuum pressure of 500 mTorr, multiple shapes of crystalized nanoparticles were produced from $\mathrm{Fe}_{3} \mathrm{O}_{4}$ including rods, spheres, triangles, and diamond shapes. It was observed that as pressure increases, nanocrystals will nucleate. This synthetic process that Cha, H.G., et al. studied "is environmentally friendly and economical because it uses nontoxic and inexpensive reagents and solvents," so when applied to a larger industrial scale, there will be less pollution than other methods [25]. 
The concentration of precursors and type of solvent used can also be used to affect the shape. The concentration of the reducing agents, ion sources, or capping agent will affect the growth rate, changing the particle shape. Using different solvents offers different functional groups that can react with the precursor monomer. By changing the solvent used in the synthesis, the particle shape that forms can be controlled [4]. Rosenfeldt, S., et al. conducted a study where they used sodium-oleate and iron salt to synthesize a metal-oleate precursor. It was found that when using a greater excess of sodium-oleate, the particles would synthesize as cubes instead of spheres like they formed with a smaller excess of sodium-oleate [3]. This is one example of how changing the solvent/concentration can contribute to shape-control synthesis. An example of how precursors can be used for shape synthesis is shown in a study by Han, L., et al. A solution of $0.49 \mathrm{M} \mathrm{Zn}\left(\mathrm{CH}_{3} \mathrm{COO}\right)_{2}{ }^{*} \mathrm{H}_{2} \mathrm{O}, 0.01 \mathrm{M} \mathrm{Al}\left(\mathrm{NO}_{3}\right)_{3}$, $(\mathrm{Zn} / \mathrm{Al}=98: 2), 0.1 \mathrm{M} \mathrm{NaOH}$, and $0.17 \mathrm{mM}$ sodium citrate was used with Al-doped $\mathrm{ZnO}$ to form platelets, while a solution of $0.49 \mathrm{M} \mathrm{ZnCl}_{2}, 0.01 \mathrm{mM} \mathrm{AlCl}_{3},(\mathrm{Zn} / \mathrm{Al}=98: 2)$ and $0.1 \mathrm{mM} \mathrm{PEG} 20000$ after adjusting the $\mathrm{pH}$ value to 7-8 using aqueous ammonia was used to form rods [13]. Both methods used a hydrothermal technique to synthesize the shapes, the platelets at $95{ }^{\circ} \mathrm{C}$ for 24 hours, and the rods at $160{ }^{\circ} \mathrm{C}$ for 20 hours which also shows again how heat can also have a part in controlling particle shape during synthesis. The method of concentration of materials and type of solvent is also used in a study by Sofianos, V. M., et al. where synthesized zinc oxide is used to produce hydrogen in a renewable way [11]. This is conducted by using sodium hydroxide to form $\mathrm{ZnO}$ nanoparticles in the shapes of cuboids, spheres, and wires. The sodium hydroxide was added to a solution of zinc acetate and absolute ethanol at three different concentrations to achieve $\mathrm{pH}$ levels of 8,10 , and 12 which formed nano wires, cuboids, and spheres, respectively [11]. It was concluded that the spherical shaped nanoparticles had the highest electrocatalytic activity; however, all three particle shapes had higher electrocatalytic activities toward hydrogen production (splitting of water) than unloaded carbon control. Due to the high catalytic activity shown by this method, advancements can be made to produce clean hydrogen.

Because methods like these have been studied and proven to work in shape control synthesis, they can be further studied and applied to the cleaner energy solutions outlined previously under the "Motivation" heading. Although these methods have been shown to be effective in shape control synthesis of nanoparticles, the progress and development of shape control is mostly trial and error [5]. The reproducibility can be challenging due to the number of variables like material, heating method, temperature, and environment. By using more controlled environments such as autoclaves or humidity-controlled rooms, some of these inconsistencies can be irradicated.

\section{Conclusion}

As can be seen, shape control synthesis of nanoparticles is an important part of engineering and innovation in the decarbonization process. The shape of a nanoparticle affects properties like stiffness, tensile strength, and hardness as well as functions like the particles ability to distribute, improve adhesion and catalysis, and promote self-assembly. These improved abilities are being used to combat carbon emissions, improve solar technology, and create more efficient batteries. Methods that use thermodynamics and kinetics including the use of capping agents, microwave synthesis, the use of an autoclave, and different concentrations and types of solvents were shown to have the ability to control the shape of nanoparticles during synthesis. While each method produced different shapes, all showed that you can start with one shape and have it change to another depending on the variables that are modified like temperature, concentration, and materials used. By proving these methods are successful, shape control synthesis can be better implemented into combatting energy waste and carbon emissions. Although these methods were successful at shape control synthesis in nanoparticles, the shape control process remains complex and requires trial and error to produce desired results.

\section{Acknowledgements}

This work was performed by Battelle Energy Alliance, LLC, under Contract No. DE-AC07-05-ID14517 with the U.S. Department of Energy, Office of Nuclear Energy. The student internship for Joy Morin was supported by the U.S. DOE Office of Science, Office of Workforce Development for Teachers and Scientists under the Science Undergraduate Laboratory Internship program. 


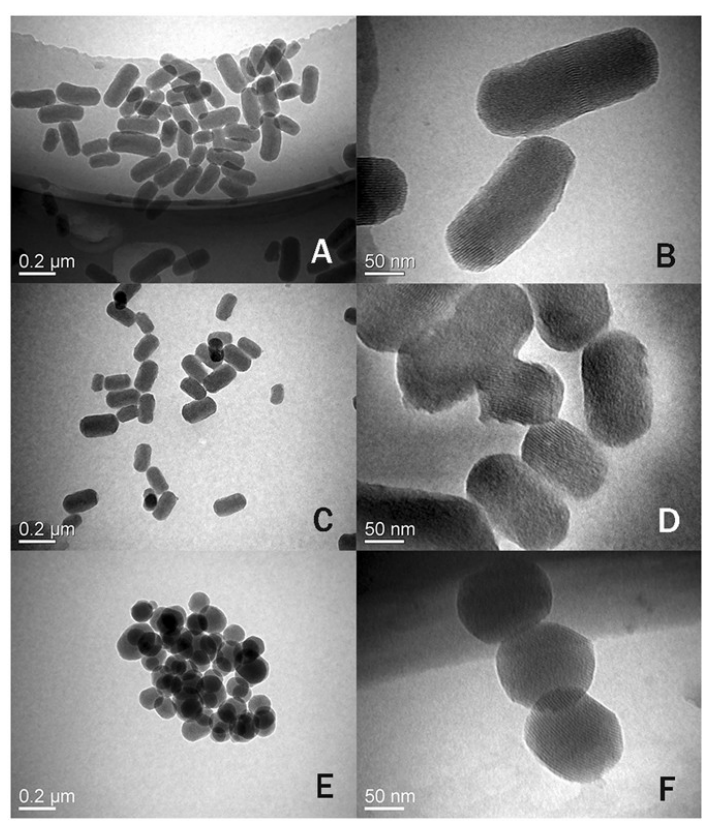

Figure 1: Rod shaped fluorescent mesoporous silica nanoparticles (a-d) and sphere shaped fluorescent mesoporous silica nanoparticles (e-f) [26] Used under a Creative Commons CC-BY license.

Figure 3: Silver nanocubes synthesized at different growth times from Sun, Y., Xia, Y. Shape-Controlled Synthesis of Gold and Silver Nanoparticles. Science (New York, N.Y.). (2003). 298. 2176-9.

10.1126/science.1077229. Reprinted with permission from AAAS [28]

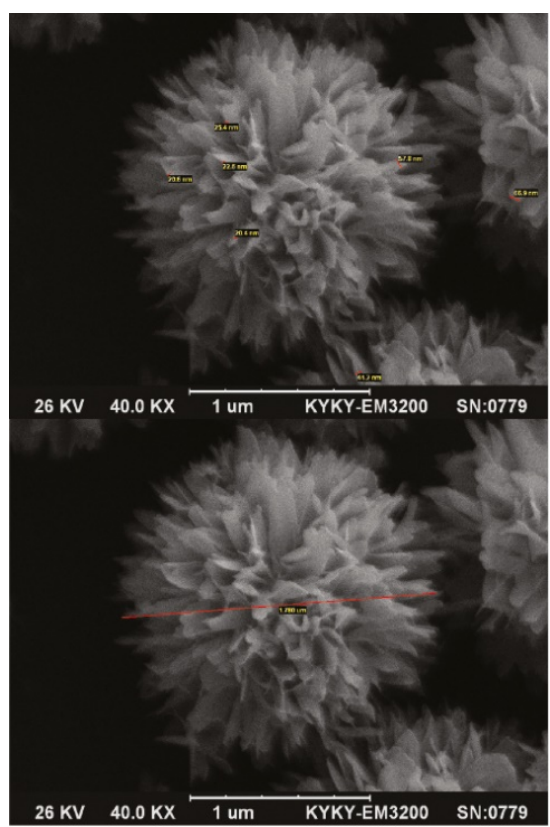

Figure 2: Flower-like SEM images of PbS obtained in the presence of glucose (capping agent) [27] Used under Open Access Creative Commons AttributionNonCommercial-NoDerivs 3.0 Unported license.

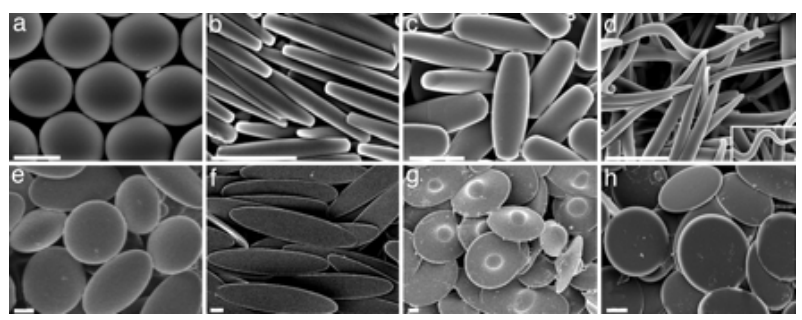

Figure 4: Micrographs of shapes made by using scheme showing different platelet shapes (e, f, $g$, and h) from Champion, J.A., Katare, Y.K., Mitragotri, S. Making polymeric micro- and nanoparticles of complex shapes PNAS July 17, (2007) 104 (29) 11901-11904; https://doi.org/10.1073/pnas.0705326104. Copyright (2007) National Academy of Sciences, U.S.A. Reprinted with permission from PNAS [29] 

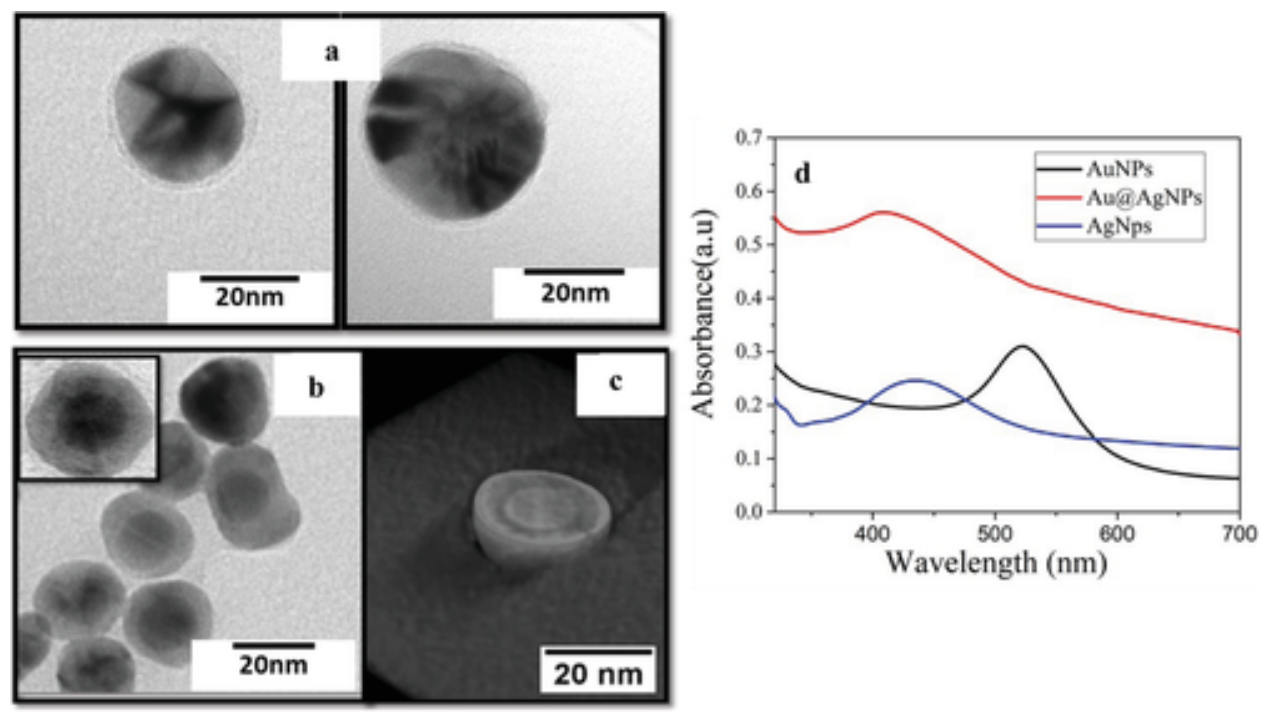

Figure 5: (a)-(c) TEM images of Au@Ag (Core-shell bimetallic plasmonic NPs consisting of gold NPs as core material and silver as shell) nanoparticles showing shell geometry (d) UV-VIS absorbance spectrum [30] Used under the Creative Commons Attribution-

NonCommercial-NoDerivs License
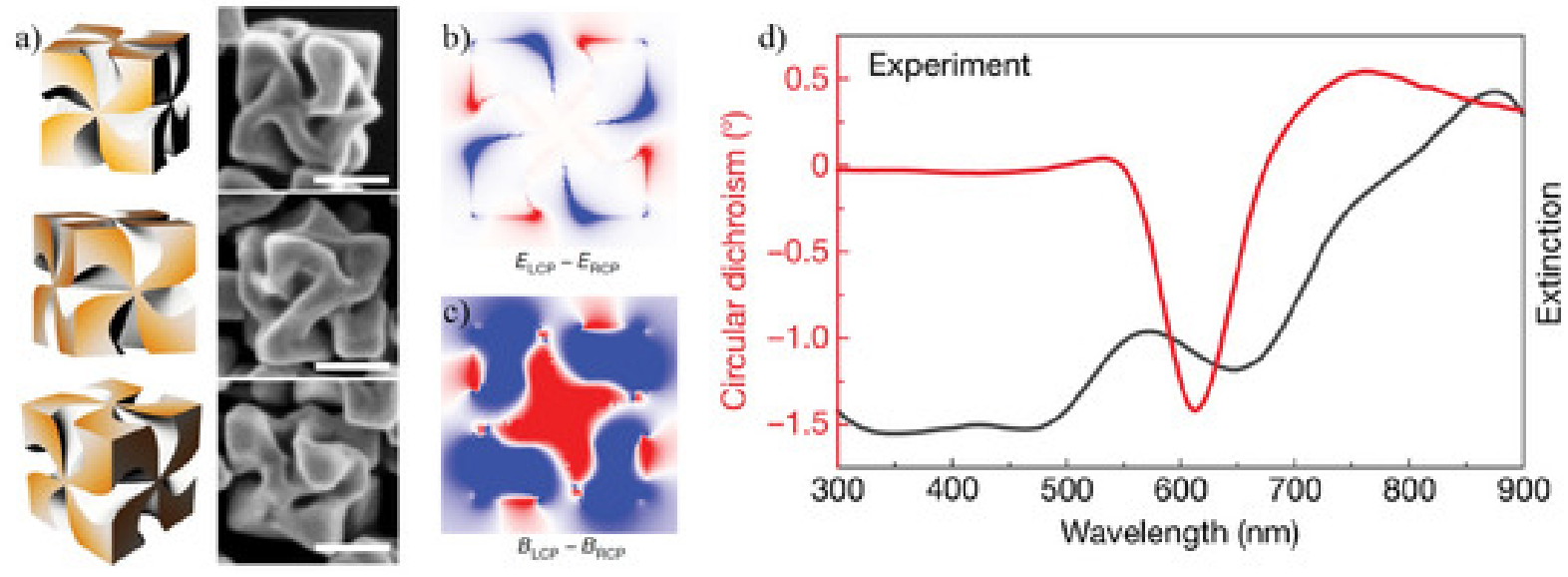

Figure 6: (a) 3D and SEM images of nanoparticles with chiral geometrv, (c) magnetic B near-fields, and (d) circular dichroism signals [31] Used under the Creative Commons Attribution License. 


\section{References}

[1] What are nanoparticles? Definition, size, uses and properties.

https:/www.twi-global.com/technical-knowledge/faqs/what-are-nanoparticles Accessed 15 Sept. 2021

[2] Adams, J. Particle Size and Shape Effects in Materials Science: Examples from Polymer and Paper Systems. Clay Minerals, 28(4), 509-530. (1993). doi:10.1180/claymin.1993.028.4.03

[3] Rosenfeldt, S., Forster, S., Friedrich, T., Rehnberg, I., Weber, B. Self-assembly of magnetic iron oxide nanoparticles into cuboidal superstructures In Novel Magnetic Nanostructures; Domracheva N.; Caporali M.; Rentschler E. B. T.-N. M. N., Eds.; Elsevier, (2018); pp 165-189.

[4] Wu, Z., Yang, S., Wu, W. Shape control of inorganic nanoparticles from solution (2015). doi: 10.1039/C5NR07681A

[5] Geonmonond, R.S., Da Silva, A.G.M., Camargo, P.H.C. Controlled synthesis of noble metal nanomaterials: motivation, principles, and opportunities in nanocatalysis. Anais da Academia Brasileira de Ciências [online]. (2018), v. 90, n. 1 Suppl 1 [Accessed 7 September 2021], pp. 719-744.

[6] Wang, Y., He, J., Liu, C., Chong, W.H., Chen, H. Thermodynamics versus Kinetics in Nanosynthesis (2015) DOI: 10.1002 /anie. 201402986

[7] Marks, L.D., Peng, L. Nanoparticle shape, thermodynamics and kinetics (2016) J. Phys.: Condens. Matter 28 053001

[8] Yadav, S., Sharma, A.K., Kumar, P. Nanoscale Self-Assembly for Therapeutic Delivery. Frontiers in Bioengineering and Biotechnology (2020).

[9] Okesola, B.O., Smith, D.K. Applying low-molecular weight supramolecular gelators in an environmental setting - self-assembled gels as smart materials for pollutant removal (2016) DOI: 10.1039/C6CS00124F (Review Article) Chem. Soc. Rev., 2016, 45, 4226-4251

[10] Neal, R.D., Hughes, R.A., Preston, A.S., Golze, S.D., Demille, T.B., Neretina, S. Substrate-immobilized noble metal nanoplates: a review of their synthesis, assembly, and application. J. Mater. Chem. C, (2021),9, 12974-13012

[11] Sofianos, V.M., Lee, J., Silvester, D.S., Samantha, P.K., Paskevicius, M., English, N.J., Buckley, C.E. Diverse morphologies of zinc oxide nanoparticles and their electrocatalytic performance in hydrogen production (2020) https://doi.org/10.1016/j.jechem.2020.07.051

[12] Seher, J., Froba, M. Shape Matters: The Effect of Particle Morphology on the Fast-Charging Performance of LiFePO4/C Nanoparticle Composite Electrodes ACS Omega. (2021) Sep 21; 6(37): 24062-24069

[13] Han, L., et al. Effects of morphology on the thermoelectric properties of Al-doped ZnO. RSC Adv., (2014), 4, 12353 DOI: $10.1039 / \mathrm{c} 3 \mathrm{ra} 47617 \mathrm{k}$

[14] Verma, S. K., Tiwari, A. K., Application of Nanoparticles in Solar collectors A Review Materials Today: Proceedings 2 ( 2015 ) $3638-3647$

[15] Caldorera-Moore, M., Guimard, N., Shi, L., Roy., K. Designer nanoparticles: incorporating size, shape and triggered release into nanoscale drug carriers. Expert opinion on drug delivery vol. 7,4 (2010): 479-95. doi:10.1517/17425240903579971

[16] Zhu, W., Kattel, S., Jiao, F., Chen, J.G. Shape-Controlled CO2 Electrochemical Reduction on Nanosized Pd Hydride Cubes and Octahedra. United States: N. p., (2019). Web. https://doi.org/10.1002/aenm.201802840.

[17] Javed, R., Zia, M., Naz, S., Aisida, S.O., Ain, N.U., Ao, Q. Role of capping agents in the application of nanoparticles in biomedicine and environmental remediation: recent trends and future prospects. J Nanobiotechnol 18, 172 (2020). https://doi.org/10.1186/s12951-020-00704-4 
[18] Safo, I.A., Dosche, C., Özaslan, M. Effects of Capping Agents on the Oxygen Reduction Reaction Activity and Shape Stability of Pt Nanocubes (2019).

[19] Sun, Y., Mayers, B., Xia, Y. Metal Nanostructures with Hollow Interiors. Adv Mater 15: 641-646 (2003). https://doi.org/10.1002/adma.200301639

[20] Xia, X., Wang, Y., Ruditskiy, A., Xia, Y. $25^{\text {th }}$ Anniversary Article: Galvanic Replacement: A Simple and Versatile Route to Hollow Nanostructures with Tunable and Well-Controlled Properties. Adv Mater 25: 6313-6333 (2013). https://doi.org/10.1002/adma.201302820

[21] Tsuji, M. Microwave-Assisted Synthesis of Metallic Nanomaterials in Liquid Phase, Chemistry Select (2017), 2, 805. https://doi.org/10.1002/slct.201700011

[22] Wang, W., Zhu, Y. Shape-controlled synthesis of zinc oxide by microwave heating using an imidazolium salt, Inorganic Chemistry Communications, Volume 7, Issue 9, (2004) Pages 1003-1005, ISSN 1387-7003

[23] Pani, A., Lee, J.H., Yun, S.I. Autoclave mediated one-pot-one-minute synthesis of AgNPs and Au-Ag nanocomposite from Melia azedarach bark extract with antimicrobial activity against food pathogens. Chemistry Central Journal 10, 15 (2016).

[24] Mi, Y., Hu, W., Dan, Y., Liu, Y. Synthesis of carbon micro-spheres by a glucose hydrothermal method, Materials Letters, Volume 62, Issues 8-9, (2008).

[25] Cha, H.G., Lee, D.K., Kim, Y.H., Kim, C.W., Lee, C.S., Kang, Y.S. Solventless Nanoparticles Synthesis under Low Pressure Inorg. Chem. (2008), 47, 1, 121-127 https://doi.org/10.1021/ic701570z

[26] Zhao, Y., Wang, Y., Ran, F., Cui, Y., Liu, C., Zhao, Q., Gao, Y., Wang, D., Wang, S. A comparison between sphere and rod nanoparticles regarding their in vivo biological behavior and pharmacokinetics. Sci Rep 7, 4131 (2017). https://doi.org/10.1038/s41598-017-03834-2

[27] Kord, M., Hedayati, K., Farhadi, M. Green synthesis and characterization of flower-like PbS and metal-doped nanostructures via hydrothermal method Main Group Metal Chemistry, vol. 40, no. 1-2, (2017), pp. 35-40. https://doi.org/10.1515/mgmc-2016-0046

[28] Sun, Y., Xia, Y. Shape-Controlled Synthesis of Gold and Silver Nanoparticles. Science (New York, N.Y.). (2003). 298. 2176-9. 10.1126/science.1077229.

[29] Champion, J.A., Katare, Y.K., Mitragotri, S. Making polymeric micro- and nanoparticles of complex shapes PNAS July 17, (2007) 104 (29) 11901-11904; https://doi.org/10.1073/pnas.0705326104

[30] Womiloju, A.A., Höppener, C., Schubert, U.S., Hoeppener, S. Microwave-Assisted Synthesis of Core-Shell Nanoparticles -Insights into the Growth of Different Geometries (2020) https://doi.org/10.1002/ppsc.202000019

[31] Paiva-Marques, W.A., Gómez, F.R., Oliveira Jr., O.N. Chiral Plasmonics and Their Potential for Point-of-Care Biosensing Applications Sensors (2020), 20(3), 944; https://doi.org/10.3390/s20030944 